\title{
NoN-Hierarchical SERViCES NeTWORKS, STEERED By COMPETENCE CELlS
}

\author{
Teich, T., Junghans, S., Trommer, M. \& Kretz, D.
}

Abstract: Global change is having a marked effect on economic and social livelihoods. Especially apparent are demographic developments and the changes in the demand for goods and services. As a consequence of a variety of problems, there is an overall lack of novel concepts for networking customer-oriented, service companies in both rural areas and the urban centres. Potential synergetic effects between providers remain ignored and freshly minted, innovative service concepts are cut short in their development. This begs the fundamental question: How can future service providers be connected to reliable, customer-oriented, non-hierarchical, regional networks, so that they can counteract developments in the service structure brought about by global change, while also identifying potential synergies and putting them into effect? The aim is to develop non-hierarchical service networks, steered by competence units, based on digital district information.

Key words: Competence Cells; Intelligent Services; regional networks; Global change
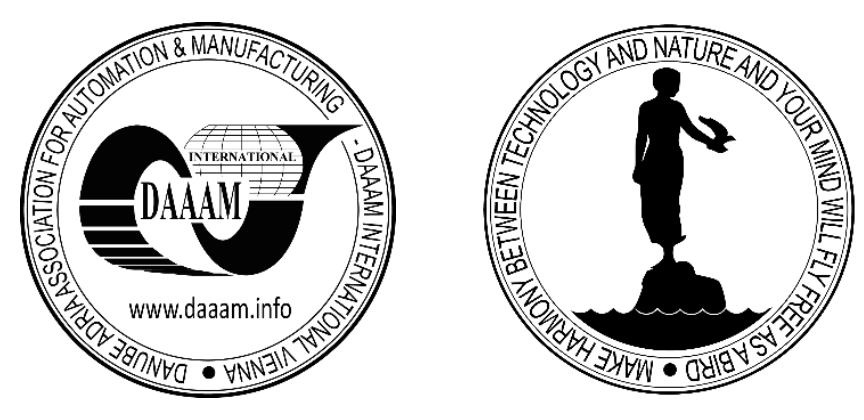

Authors' data: Prof. Dr. rer. pol. habil. Dr.-Ing. Teich, T[obias]*; MSc. Junghans, S[ebastian]*; MSc. Kretz, D[aniel]*; MSc. Trommer, M[artin]*, * University of Applied Sciences Zwickau, Dr.-Friedrichs-Ring 2A, 08056 Zwickau, Germany, tobias.teich@fh-zwickau.de, sebastian.junghans@fh-zwickau.de, daniel.kretz@fhzwickau.de, Martin.Trommer.1fw@fh-zwickau.de

This Publication has to be referred as: Teich, T[obias]; Junghans, S[ebastian]; Kretz, D[aniel] \& Trommer, M[artin] (2016). Non-Hierarchical Services Networks, Steered by Competence Cells, Chapter 10 in DAAAM International Scientific Book 2016, pp.103-112, B. Katalinic (Ed.), Published by DAAAM International, ISBN 978-3902734-09-9, ISSN 1726-9687, Vienna, Austria

DOI: $10.2507 /$ daaam.scibook.2016.10 
Teich, T.; Junghans, S.; Kretz, D. \& Trommer, M.: Non-Hierarchical Services Net...

\section{Introduction}

In addition to adverse climatic and environmental conditions, global change is having a profound effect upon people's economic and social means of livelihood. Particularly apparent are demographic developments and constant changes in the trade of goods and services. The effects of demographic transition are going to become increasingly significant.

Decreasing birth rates, rising life expectancy, lower incomes in old age and current migratory trends are going to present appreciable economic and social problems (Geyer \& Steiner, 2010). Rural districts and smaller municipalities will see the proportion of older people dramatically increase, while younger people move away to take advantage of the opportunities in urban centres. This will produce a knock-on effect of depleted resources in rural areas which will hinder the introduction of any new and innovative service concepts there.

On the other hand, cities with high population increase rates will have similar problems for different reasons. The problems will arise here, because of the pressure put on existing resources, services and infrastructure by a rapid influx of ever-growing multicultural groups, requiring recombination to develop novel ideas (Bundesministerium, 2012).

Both extremes will create changes in the demand for services and pose growing challenges to community administrators and utilities providers. Both rural and urban regions are characterised by a lack of novel concepts for how companies in the service sector could better network with each other in a customer-oriented way. Service providers in urban and rural municipalities are essentially heterogeneous. They are, at most, only partially networked and there is limited social, political or economic interaction (i.e. a gap) between them within their value chain processes "Fig 1".

Every service provider concentrates on their specific service, providing the best packages within the sphere of their core competences, without having any view of potential synergies in other areas. While these services may be highly satisfactory to the customer, additional networking potential is seldom exploited and, although these companies may have a high degree of expertise, it must be remembered their resources are always limited.

Therefore, only partial sequences of value chain processes can be created. This is especially the case in the problem areas of medical care, affordable living and efficient and climate-friendly energy supply where, because of the lack of networking, methods and models, possible synergetic effects are largely overlooked.

Furthermore, most current forms of cooperation are based on hierarchical structures within and between the companies, allowing little or no cooperation on an even footing. Larger companies generally dominate proceedings both organisationally and economically. While gaining the advantage of relative stability, small companies find themselves dependent upon the larger ones and tend to lose contact with the endcustomers. The net result is that a lot of potential and competence is not fully utilised and the desired macroeconomic outcomes are hampered. 


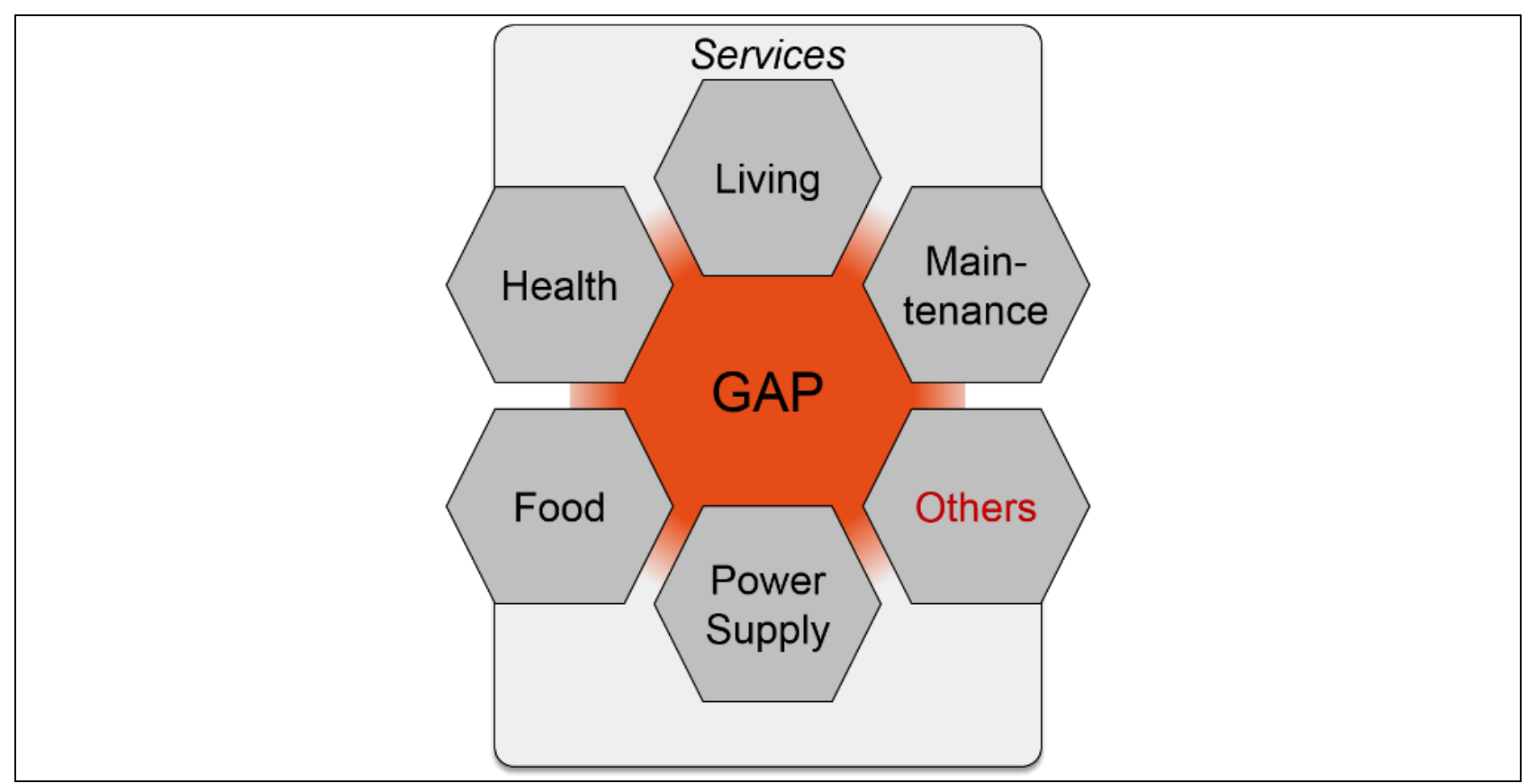

Fig. 1. Gap in the service sector

Then, there are the extensive problems associated with data protection, data security and legislation, which significantly impede any extensive network of service providers. For the sake of self-preservation, service providers avoid sharing their acquired know-how with other providers. Furthermore, exchanging business data in a networked environment has its dangers (e.g. data abuse). Moreover, the networking of service providers at the regional level is increasingly restricted by national and international regulations. At the same time, growing digitalisation in the form of 'The Internet of Things', Cloud Computing and Smart Cities shall surely influence the digital nature of networking.

To address these issues and form a secure, data-based generation of services requires creative efforts to design new service structures, which are relatively nonhierarchical, efficient networks of individual players. Currently, many service providers do not have the ways and means to develop these forward-looking structures and business processes. Against a background of global challenges, it is an indispensable prerequisite for the dynamic development of an economy, that the service sector is further strengthened by sustainable, self-supporting regional structures.

\section{Research Question}

In the light of the above, the following question demands closer inspection:

How can future service providers be connected to reliable, customer-oriented, non-hierarchical, regional networks, so that they can counteract developments in the service structure brought about by global change, while also identifying potential synergies and putting them into effect? 
Teich, T.; Junghans, S.; Kretz, D. \& Trommer, M.: Non-Hierarchical Services Net...

1. What interactions between regional and global value are there and can competitive advantages be identified?

2. How are human lives changing through the advance of digitalisation?

3. What options present themselves for the development of new service structures as a consequence of advancing digitalisation?

4. What alternative value chains for service networks might be possible in addition to the current hierarchical corporate structures, that would facilitate a largely non-hierarchical and efficient, customer-directed network based upon value-added units?

5. What influence do these alternative value chains have upon the design of service processes?

6. How are these value-creating units characterised and what are the technological and organisational conditions for their economically viable scale and networking potential?

7. What roles do human potential and the dimension of socio-cultural factors play in such alternative service structures?

8. What influence do regional aspects have upon such service structures and, conversely, how do these structures facilitate the development of a servicebased, regional economy?

9. How can new forms of employment be accessed via value-adding services, through skills integration, -addition and -disintegration and how can work and cooperation structures be derived from this?

10. Which theories, models, methods and tools are applicable and can be employed for the planning and operation of services in future networks and how can these be adapted and further developed?

Finding answers to these fundamental questions will be vital for service providers, as well as having regional, national and international importance. With the further development of the European Single Market, it is also likely that networked service structures will compete with each other globally.

\section{Research Concept}

As a starting point for addressing this research question, Fig 2 depicts the basic model of thinking, taking an integrated overview of competence, events and process orientation.

The theoretical model assumes that in any district, (neighbourhood, residential area, etc.) all physical elements such as: houses, roads, communications, etc. are present. In this district, on the one hand, there live consumers (e.g. tenants and their relatives) and on the other hand, there are companies, including service providers. In this setting, (as always), there are needs, either triggered by the consumer or excited by service provider offers. Both needs and offers are characterized by specific events that occur. These events are based upon concrete circumstances. 
Either there is a triggering event (e.g. a tenant in the neighbourhood orders a food takeaway from a service provider and has it delivered to his home) or, there is a fixed arrangement beforehand (e.g. the service provider delivers food to the tenant at regular intervals).

The district (neighbourhood) and the players therein, are observed and analysed from basically, three viewpoints: competence orientation, event orientation, process orientation.

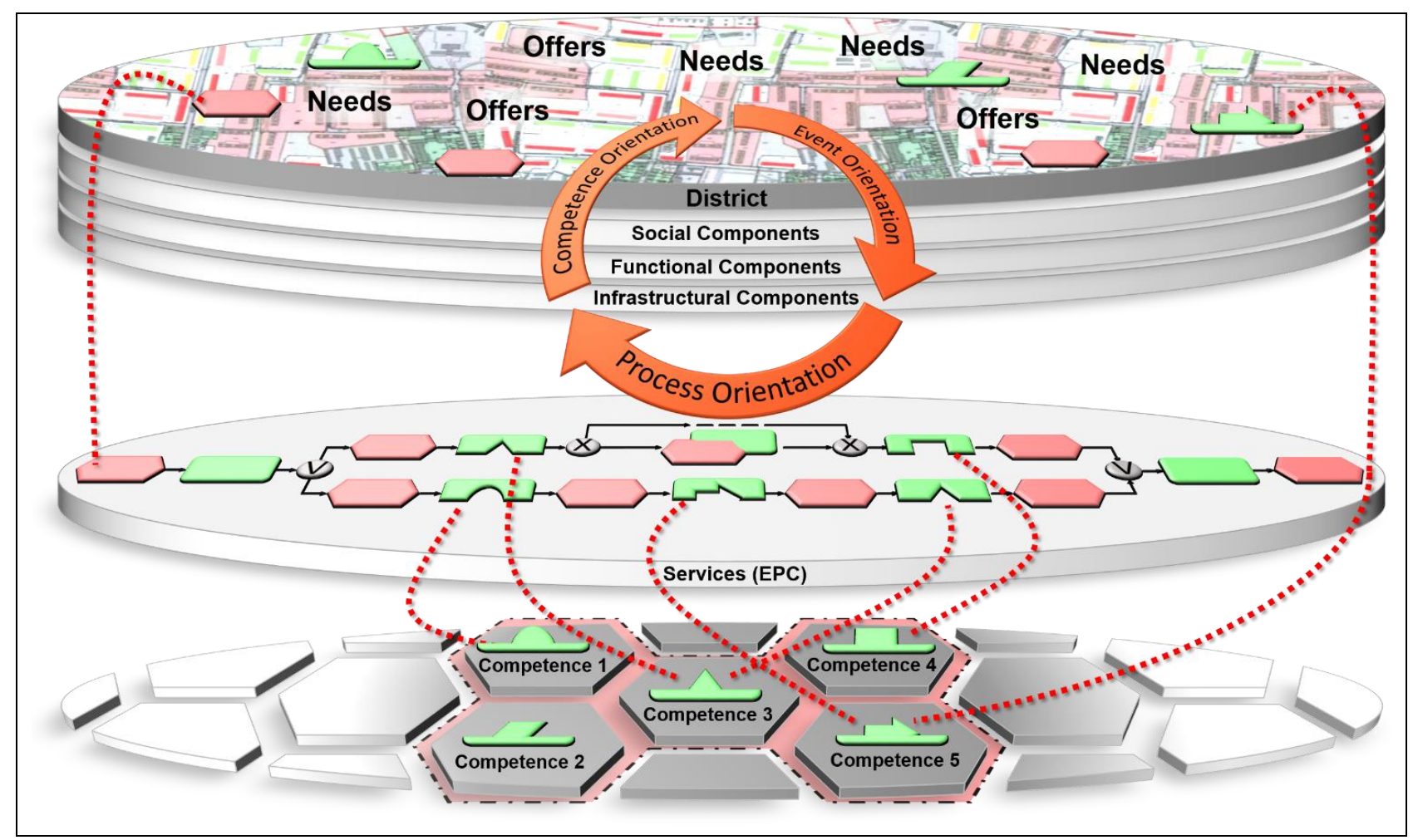

Fig. 1. Non-Hierarchical Services Networks, steered by Competence Cells, based on Digital District Information

From the perspective of competence orientation, in any district, it is necessary to establish what skills are relevant to meeting needs or creating offers and whether the service provider is already in possession of these competences.

Event orientation is determined by establishing which events are likely to trigger the service process, what the objectives are and what interactions and incompatibilities exist here.

From the point of view of event orientation, it is necessary to know which events are likely to trigger the service process, which objectives are available and where there is interaction and where there is incompatibility.

With process orientation, it is important to establish how service processes have to be modelled and implemented. The process modelling can result from e.g. eventdriven process chains (EPC).

In this way, the functions of the EPC can correspond to the concrete competences of the service providers. These occur in the process of providing services as so-called competence cells (CPC) in a district. 
A CPC "Fig. 3" ...is the smallest divisible performance unit of value. It consists of the person with his/her individual competences (competences, assets, abilities, skills and willingness) and the resources available to him/her (surface areas, stocks, employment, labour auxiliaries, and organizational resources).

They realize their resources in terms of the basic logistical functions of saving, moving and transformation.

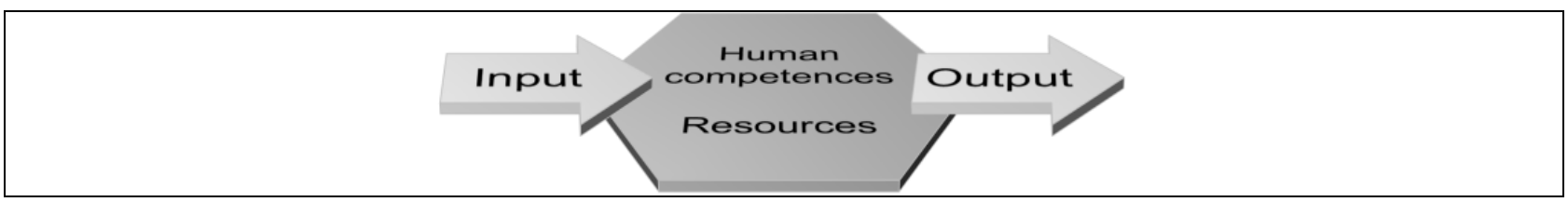

Fig. 3. Competence Cell

The CPC has the characteristics of being elementary, autonomous and viable in a network. It is integrated into a space within a district. To a large extent it is adaptable to extension, learning, and collaboration and thereby possesses the conditions for selforganisation' (Teich, 2001).

To identify and utilize unrecognized potential synergies between the CPC, they shall be enabled by appropriately developed methods to establish the required regional competence network. In general, in this competence network, the CPC is viable only as a node.

However, during the process of networking, the CPCs do not generate hierarchical structures, instead, they create peer-based, non-hierarchical partnerships and have no specific order of preference in the decision-making processes. Networking capability assumes that, present in each CPC-defined interface, data exchange relationships are possible. In this regard, both the inner and outer characteristics, as well as the CPC interfaces, yet to be described from the perspective of computer science shall be represented by a model.

Of course, CPC networking in the competence network can only take place in strict compliance with the provisions of data protection and data security. To be able to participate in a general competence network, the CPC must meet social, functional and infrastructural requirements.

The social component includes skills such as social interaction and communication, adaptability, motivation, teamwork, etc.

The functional component comprises specific subject knowledge, such as the understanding of legal frameworks, technical capabilities etc.

The infrastructural component comprises the formation of infrastructures such as: corporate structure, secure IT infrastructure, etc. For a competence network to be set up, all three elements must have the same degree of importance.

The overall concept can best be described in the following sample scenario. In one particular district, there is the requirement for medical care due to some triggering event or objective. A physician diagnoses Diabetes Mellitus Type. 2 in an elderly tenant in the district. 
The doctor recommends the patient's diet is adapted and he/she is put on insulin. It will be necessary that a nurse or health-carer measures the patient's sugar levels and administers insulin 3 times a day.

It will also be necessary that a nutrition expert shall accompany the change of diet. Since the tenant would prefer his/her food home delivered, a delivery service will be needed. The competence network will determine the CPCs possessing the relevant skills (e.g. doctors, healthcare, food services, medical supply stores etc.) for generating this service. These CPCs are networked and customer-oriented in the process of service delivery and implement this.

Through the usage of synergies, it becomes apparent, e.g., that several tenants in the district would like their food delivered and, at the same time, require similar healthcare. As a result, both the care and the food supply are undertaken by the same nursing service which produces an efficient use of resources.

After completion of the provision of services, CPCs are able to evaluate and derive innovative future options, which for the present, might not actually be required. In this way, the heterogeneous mix of service providers from the fields of medicine, computer science, housing and energy might well be inspired to develop and indeed, offer new concepts of assisted living. The successful achievement of business objectives will depend upon how effectively the CPC competences and resources are employed and how well they are brought into the service process.

For any economic region, competence deficits will rapidly show up, but can be offset by establishing a new CPC in the region or by outsourcing from outside. In addition, new findings in digitization through the growth of Big Data and the rapid development towards Smart Cities will include this new type of service generation in the future. Possibilities for abstraction are taken into account in all considerations. Only in this way can the concept be applied worldwide for all conceivable services and regions, (e.g. with demographically key regions and metropolitan areas), (scalability, design-for-all).

\section{The Current State of Research}

The Technical University in Chemnitz elaborated the basics for competence cellbased production of goods within their research activities at the 'DFG Sonderforschungsbereich 457 (SFB) Non-hierarchical regional production networks (year 2000)' and their work serves as a starting point for the proposed project. In the SFB, methods and models have been studied and developed, to examine how resident manufacturing organizations within a region can join together to form competence-cell based networks, so that a broader spectrum of tasks can be processed. The currently proposed project shall be based upon investigations into the emergence of new business in the tertiary sector and it shall transfer from this. Similarly, service providers shall be perceived as competence cells and be networked with each other on this basis, in order to tap new business process-driven fields (Teich, 2001). 
All sources approach networking from the perspective of marketing, in and outside of service networks. MANUEL MICHAELIS dedicates his dissertation 'Internal Marketing in Service Networks' in this fashion, although the design and performance measurement of the activities of such a network do not give a full representation of how these service networks emerge (Michaelis, 2009).

In his dissertation, 'Performance measurement of stochastic service productions' MARCEL ROSSMY examines the measurement and increase of effectiveness and efficiency in the provision of services. However, this work treats the (re) emergence or merger of several companies for the provision of services and the proposed project must be understood more at a grass-roots level (Rossmy, 2007).

REICHWALD UND MÖSLEIN deal with the work report of the Technical University of Munich, 'Value and productivity of services?' (Reichwald, 1995) similar to BRUHN UND HADWICH in 'Service Productivity' with innovative strategies for job security through increased productivity in the tertiary sector and thus they also connect with the proposed project (Bruhn \& Hadwich, 2011)

In 'Value-added processes in services' BRUHN UND STAUSS examine the transfer of industrial production processes to hybrid combination forms in the provision of services, referring specifically to the growing impact of adaptation, but they do not deal with the basic, process-driven development of service networks (Bruhn, 2011).

Similarly, in her dissertation,' Control of service networks' MESCHKE investigates the formation of service networks, but the underlying approach is substantially different to applied projects. Her work illuminates the mergers of existing companies from the viewpoint of qualitatively improving customer and revenuerelated needs, but confines itself to the improvement of existing services and not their expansion and recombination between individual service skills (Meschke, 2013).

To summarise, it is fair to say that previous research projects have not yet adequately ad-dressed the problem areas mentioned in this proposal. The potential arising from the digitalisation of neighborhood districts has not been tapped in current research until now and the proposed project is intended to go a long way to filling this significant gap.

\section{Expected Results and Practical Relevance}

The result of this proposed project shall be the generation of theories, models, methods and instruments with which service companies can be networked with each other, as non-hierarchical, customer-oriented CPCs.

The CPCs are thus able to plan secure networks to operate within and to independently acquire orders on the net. The basic learning principles are, inter alia, the impact of digitalisation on the living environment and how the living environment shall further develop.

In particular, the most useable information in districts shall be highlighted to assess its relevant working potential. Furthermore, factors such as socio-cultural aspects, interactions (e.g. between regional and global value creation) and human 
potential shall be determined and further examined. As part of the consideration of privacy and data security, among others, a catalogue of requirements for the safety of service networks shall be established.

In addition, all relevant legal aspects shall be evaluated and merged into one concept. In the context of elementarisation and the networking of CPCs, methods for modelling and the assessment of competence cells shall be created, as well as methods for the competence integration, addition, and -disintegration of new value added services. This shall contribute to a generic model for CPCs and the networking, social, functional and infrastructural requirements for them to participate in service networks alongside methods to monitor competence, event and process orientation.

In addition, work, cooperation and communication structures for service networks shall be formed. As a basis for the implementation of complex services processes and systems, methods and instruments for the planning and operation of digital service systems shall be created for the (operational) service management as well as the model of an information technology core.

In an optional fifth year, the model of a specific process in the demonstration environment and a model of a network of services for the operationalisation of the processes will also be developed and implemented for illustration.

The principles developed in this project (theories, models, methods and instruments) shall be practically applied to finding new value chains and processes, new combinations of existing competences and thereby, the need for new services might be expected.

For global change, this means that for demographically challenged areas, as well as thriving urban centres, the existing service resources for consumers in a district can be made available more efficiently, more effectively and faster. This will lead to the emergence of new forms of organisation and working models in the tertiary sector, which will no longer be comparable with today's centrally structured cooperation structures.

This new type of service networking shall accommodate the future, growing pace of customer requirements and lead to dynamic networks with convertible structures in value. A customer-oriented, non-hierarchical, regional service network geared to holistic service provision, thus utilises the synergies of each CPC.

In addition, an economically desired momentum is likely to counteract some of

the negative effects upon the service structure, generated by globalisation-related developments.

\section{References}

Bruhn, M., Hadwich, K.: Dienstleistungsproduktivität - Innovationsentwicklung, Internationalität, Mitarbeiterperspektive; Band 2; Springer Fachmedien Wiesbaden GmbH; Wiesbaden 2011; ISBN: 3834928011 
Teich, T.; Junghans, S.; Kretz, D. \& Trommer, M.: Non-Hierarchical Services Net...

Bruhn, M., Stauss, B.: Wertschöpfungsprozesse bei Dienstleistungen - Forum Dienstleistungsmanagement; GWV Fachverlage GmbH; Wiesbaden 2007; ISBN 9783834944139

Bundesministerium des Inneren: Demografiebericht - Bericht der Bundesregierung zur demografischen Lage und künftigen Entwicklung des Landes; In: https://www.bmi.bund.de/SharedDocs/Downloads/DE/Broschueren/2012/demografie bericht.pdf?blob=publicationFile; Zugriff am 26.10.2015; BMI; 2011

Geyer, J., Steiner V.: Künftige Altersrenten in Deutschland: Relative Stabilität im Westen, starker Rückgang im Osten; Deutsches Institut für Wirtschaftsforschung; Wochenbericht 11/2010, S.3-11, S.12-19

Meschke, M.: Steuerung in Dienstleistungsnetzwerken - Ein Ansatz für ein integriertes Qualitätsinformationssystem; Springer Fachmedien Wiesbaden GmbH; Wiesbaden 2013; ISBN: 3658035544

Michaelis, M.: Internes Marketing in Dienstleistungsnetzwerken - Konzeption und Erfolgsmessung; GWV Fachverlage GmbH; Wiesbaden: Gabler, 2009; ISBN:9783834982728

Reichwald, R., Möslein, K.: Wertschöpfung und Produktivität - Innovationsstrategien für die Standortsicherung; Arbeitsbericht Nr. 6 des Lehrstuhls für Allgemeine und Industrielle Betriebswirtschaftslehre der Technischen Universität München; München 1995; ISSN 09425098

Rossmy, M.: Leistungsmessung stochastischer Dienstleistungsproduktionen; Deutscher Universitätsverlag; Auflage: 2007; Wiesbaden; ISBN: 978-3835008618.

Teich, T. (Hrsg.): Hierarchielose Regionale Produktionsnetzwerke; 1.Auflage; Verlag der Gesellschaft für Unternehmensrechnung und Controlling mbH; Chemnitz 2001; ISBN: 978-3934235182; S. 2-19 